\title{
MOLYBDENUM ABUNDANCE IN SOME OPEN CLUSTERS
}

\author{
Shereta E. ${ }^{1}$, Carraro G. ${ }^{2,3}$, Gorbaneva T. ${ }^{1}$, Mishenina T. ${ }^{1}$ \\ ${ }^{1}$ Astronomical Observatory, Odessa National University, Shevchenko Park, 65014 Odessa, \\ Ukraine \\ ${ }^{2}$ European Southern Observatory, Alonso de Cordova 3107, 19001 Santiago de Chile, Chile \\ ${ }^{3}$ Dipartimento di Fisica e Astronomia, Universita di Padova, Italy
}

ABSTRACT. This paper presents the results of determination of the molybdenum abundances in $13 \mathrm{G}, \mathrm{K}$ type stars in the open clusters NGC 2477 and NGC 2506. The abundances of molybdenum were determined using stellar atmosphere models by Castelli \& Kurucz (2004), as well as a modified STARSP LTE spectral synthesis code (Tsymbal, 1996). For the used Mo I lines 5506 and $5533 \AA$ the oscillator strengths $\log g_{f}$ were adopted from the latest version of the VALD database dated 2016 (Kupka et al., 1999). The high resolution spectra were obtained with a VLT telescope at the European Southern observatory (ESO, Chile).

We used atmospheric parameters of the investigated stars which we had obtained earlier. We have found out that the molybdenum abundances depend on metallicity $[\mathrm{Fe} / \mathrm{H}]$ in giants of NGC 2506 and NGC 2477. For the stars in NGC 2506, molybdenum is slightly overabundant as compared to the solar abundance; such an overabundance is slightly higher in the stars of the second investigated cluster NGC 2477. Further investigation of the Mo abundance in larger number of open clusters is required to draw reliable conclusions.

Keywords: stars: abundances - stars: late-type - Galaxy: disc - Galaxy: evolution.

АБСТРАКТ. Наведено результати визначення вмісту молібдену в 13 зорях спектральних класів G, K, розсіяних скупчень NGC 2477 та NGC 2506. Вміст молібдену визначається за моделями атмосфери Кастеллі і Куруц (2004) та модифікованим кодом спектрального синтезу STARSP LTE. Для використовуваних ліній Мо I 5506 та $5533 \AA$ сили осциляторів $\log g_{f}$ були взяті з останньої версії (2016) бази даних VALD (Купка та ін., 1999). Спектри високої роздільної здатності були отримані за використання телескопу VLT Європейської південної обсерваторії (ESO, Чилі).

Атмосферні параметри досліджуваних зір були отримані нами раніше. Ми виявили залежність величини вмісту молібдену від металичності $[\mathrm{Fe} / \mathrm{H}]$ у гігантів скупчень NGC 2506 та NGC 2477. Для зір скупчення NGC 2506 ми отримали малі надлишки вмісту молібдену від сонячного значення і дещо більші для другого досліджуваного скупчення - NGC 2477. Необхідно додатково досліджувати вміст Мо в багатьох РС для отримання більш надійних висновків.

\section{Introduction}

Stellar clusters are groups of loosely gravitationally bound stars which were formed from one and the same gas-and-dust cloud and have similar kinematics and chemical composition.

Open clusters (OC) belong to the plane of the Galactic disc. The age of OCs vary from few Myr to several Gyr. The stellar density in OCs is lower than in globular clusters (GCs) and is decreasing towards the cluster centre. The metallicity $[\mathrm{Fe} / \mathrm{H}]$ of the $\mathrm{OC}$ stars is close to that of the Sun and may differ by a factor of 5 . For older clusters, $[\mathrm{Fe} / \mathrm{H}]$ decreases with increasing distance from the centre of the Galaxy, and on average, it is lower than metallicities of the clusters formed later.

This paper presents the molybdenum abundances estimated for two open clusters, namely NGC 2477 and NGC 2506. The target stars in this study are the $\mathrm{G}$ and $\mathrm{K}$ type red giants.

It is known that molybdenum is produced in several different processes, such as slow neutron-capture (sprocess), rapid neutron-capture (r-process) and protoncapture (p-process) processes.

Mo is a highly convolved element that receives contributions from both the s-process and the p-process and less from the main and weak r-processes (see, e.g. Hansen et al., 2014).

The study of molybdenum is of interest for several reasons: there is limited number of determinations of the molybdenum abundance in the open cluster stars; and virtually, there have been no observations of the field stars with the solar metallicities. At the same time, an important feature of molybdenum is that current model calculations of nucleosynthesis do not describe its contribution to the relevant solar abundance. The data which we obtained make it possible to investigate the ways of production of molybdenum and its enrichment in both individual components of the Galaxy and the entire Galaxy itself.

\section{Observation data. Basic parameters of the inves- tigated clusters and constituent stars}

The spectra used in this study had been obtained earlier by G. Carraro with the multi-object fibre-fed FLAMES facility mounted at the VLT/UT2 telescope at the Paranal Observatory operated by the European Southern Observatory (ESO) in Chile. Either two or three exposures (depending on the cluster; Table 1) were taken with the red arm of 
the UVES high-resolution cross-dispersed echelle spectrograph. The UVES spectrograph was set up at the central wavelength $5800 \AA$ thereby covering the 4760-6840 $\AA$ wavelength range and providing a resolution $R=47000$.

The following basic parameters of the investigated clusters are listed in Table 1: Galactic coordinates (for J2000.0); Galactocentric distance $R \mathrm{GC}$ and age. More detailed information on the data sources can be found in (Mishenina et al., 2015).

Table 1: Basic parameters of the investigated clusters

\begin{tabular}{|c|c|c|c|c|c|}
\hline $\begin{array}{c}\text { Name of } \\
\text { cluster }\end{array}$ & $l,(\mathrm{deg})$ & $b,(\mathrm{deg})$ & $\begin{array}{c}R_{G C,} \\
(\mathrm{kpc})\end{array}$ & $\begin{array}{c}\text { age, } \\
(\mathrm{Gyr})\end{array}$ & $\begin{array}{c}V, \\
(\mathrm{mag})\end{array}$ \\
\hline $\begin{array}{c}\text { NGC } \\
2477\end{array}$ & 253.563 & $\begin{array}{c}- \\
05.838\end{array}$ & 8.9 & 0.6 & $+5,8$ \\
\hline $\begin{array}{c}\text { NGC } \\
2506\end{array}$ & 230.564 & 9.935 & 10.9 & 1.9 & $+7,6$ \\
\hline
\end{tabular}

As can be seen in Table 1, the cluster NGC 2506 is older and more distant from the Galactic centre than the NGC 2477 cluster.

Earlier, we have determined the atmospheric parameters and chemical abundances of the stars in the clusters NGC 2477 and NGC 2506 (Mishenina et al., 2015).

The following basic and atmospheric parameters are given in Table 2: the ICRS coordinates; photometric data $(V, B-V)$; effective temperatures $T_{e f f}$; gravity factor $\log g$; microturbulent velocity $\mathrm{V}_{t}$; metallicity $[\mathrm{Fe} / \mathrm{H}]$ and radial velocity $\mathrm{V}_{r}$.

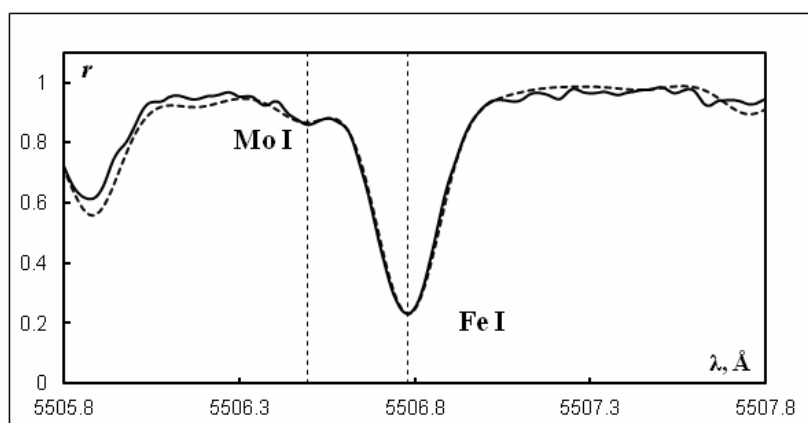

Figure 1: An example of the observed and synthetic spectra in the region near the Mo I $5506.493 \AA$ line for the star 5271 in the NGC 2506 cluster.

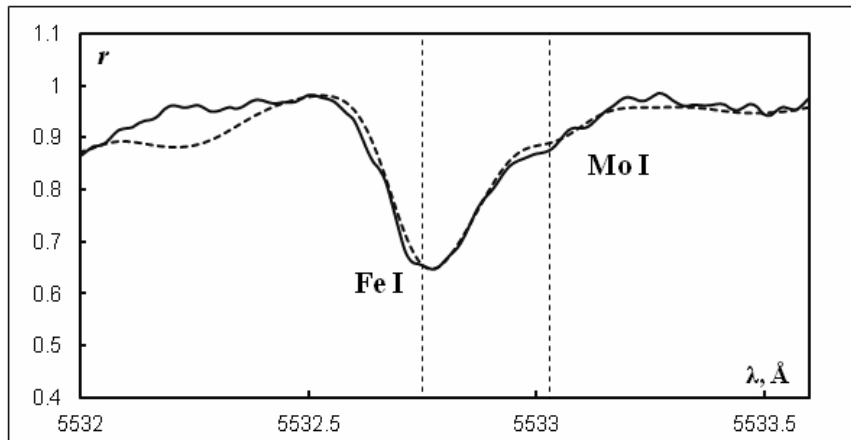

Figure 2: An example of the observed and synthetic spectra in the region near the Mo I 5533.031 $\AA$ line for the star 5271 in the NGC 2506 cluster.

Table 2: Basic data and atmospheric parameters of the investigated stars

\begin{tabular}{|c|c|c|c|c|c|c|c|c|c|}
\hline $\begin{array}{c}\text { Star } \\
\text { number }\end{array}$ & $\begin{array}{l}\mathrm{RA}(2000.0) \\
\text { (deg) }\end{array}$ & $\begin{array}{c}\operatorname{Dec}(2000.0) \\
(\mathrm{deg})\end{array}$ & $\begin{array}{c}V, \\
\text { (mag) }\end{array}$ & $\begin{array}{l}B-V, \\
(m a g)\end{array}$ & $\begin{array}{l}\mathrm{T}_{\text {eff }} \\
(K)\end{array}$ & $\begin{array}{c}\log \\
g\end{array}$ & $\begin{array}{c}\mathrm{V}_{t} \\
(\mathrm{~km} / \mathrm{s})\end{array}$ & {$[\mathrm{Fe} / \mathrm{H}]$} & $\begin{array}{c}\mathrm{V}_{r} \\
(\mathrm{~km} / \mathrm{s})\end{array}$ \\
\hline \multicolumn{10}{|c|}{ NGC 2477} \\
\hline 4027 & 118.087917 & -38.577194 & 12.153 & 1.198 & 4966 & 2.7 & 1.4 & 0.1 & $7.03 \pm 0.13$ \\
\hline 4221 & 118.152083 & -38.631750 & 12.27 & 1.171 & 4975 & 2.8 & 1.2 & 0.19 & $8.80 \pm 0.23$ \\
\hline 5043 & 118.040417 & -38.598306 & 12.165 & 1.17 & 5001 & 2.8 & 1.2 & 0.08 & $13.22 \pm 0.27$ \\
\hline 5076 & 118.061667 & -38.629194 & 12.41 & 1.22 & 4954 & 2.7 & 1.2 & 0.18 & $9.22 \pm 0.33$ \\
\hline 7266 & 117.955000 & -38.535694 & 12.252 & 1.193 & 4966 & 2.8 & 1.2 & 0.19 & $9.30 \pm 0.14$ \\
\hline 7273 & 117.947917 & -38.543389 & 12.39 & 1.174 & 4985 & 2.8 & 1.2 & 0.2 & $8.77 \pm 0.51$ \\
\hline 8216 & 118.064583 & -38.457306 & 12.334 & 1.272 & 4945 & 2.7 & 1.2 & 0.14 & $3.99 \pm 0.50$ \\
\hline \multicolumn{10}{|c|}{ NGC 2506} \\
\hline 1112 & 120.013750 & -10.762250 & 12.961 & 0.958 & 4969 & 2.6 & 1.2 & -0.22 & $83.99 \pm 0.27$ \\
\hline 1229 & 120.030833 & -10.740722 & 13.118 & 1.011 & 4728 & 2.4 & 1 & -0.22 & $82.54 \pm 0.58$ \\
\hline 2109 & 120.029583 & -10.779000 & 13.146 & 0.89 & 5040 & 2.6 & 0.9 & -0.22 & $89.31 \pm 0.05$ \\
\hline 2380 & 120.038750 & -10.818806 & 13.187 & 0.927 & 4992 & 2.6 & 1 & -0.19 & $83.64 \pm 0.53$ \\
\hline 3231 & 119.982917 & -10.805944 & 13.105 & 0.952 & 4974 & 2.6 & 1.2 & -0.22 & $84.36 \pm 0.51$ \\
\hline 5271 & 120.028750 & -10.752000 & 13.204 & 0.923 & 4993 & 2.6 & 1.1 & -0.24 & $83.52 \pm 0.15$ \\
\hline
\end{tabular}


Table 3: The resulting Mo abundance determinations, rms deviations $\sigma$ and metallicities $[\mathrm{Fe} / \mathrm{H}]$ (Mishenina et al., 2015) for 13 giants in NGC 2477 and NGC 2506.

\begin{tabular}{|c|c|c|c|c|}
\hline \multicolumn{5}{|c|}{ NGC 2477} \\
\hline Star number & {$[\mathrm{Fe} / \mathrm{H}]$} & $\pm \sigma$ & {$[\mathrm{Mo} / \mathrm{H}]$} & $\pm \sigma$ \\
\hline 4027 & 0.1 & 0.12 & -0.12 & 0.14 \\
\hline 4221 & 0.19 & 0.09 & -0.19 & 0.06 \\
\hline 5043 & 0.08 & 0.12 & -0.23 & 0.14 \\
\hline 5076 & 0.18 & 0.12 & -0.14 & 0.12 \\
\hline 7266 & 0.19 & 0.12 & -0.08 & 0.08 \\
\hline 7273 & 0.2 & 0.1 & -0.11 & 0.07 \\
\hline 8216 & 0.14 & 0.12 & -0.24 & 0.06 \\
\hline & NGC 2506 & & \\
\hline Star number & {$[\mathrm{Fe} / \mathrm{H}]$} & $\pm \sigma$ & {$[\mathrm{Mo} / \mathrm{H}]$} & $\pm \sigma$ \\
\hline 1112 & -0.22 & 0.1 & -0.12 & 0.19 \\
\hline 1229 & -0.22 & 0.11 & -0.4 & 0.12 \\
\hline 2109 & -0.21 & 0.17 & -0.09 & 0.07 \\
\hline 2380 & -0.19 & 0.13 & -0.23 & 0.35 \\
\hline 5271 & -0.22 & 0.13 & -0.22 & 0.09 \\
\hline 3231 & -0.24 & 0.12 & -0.11 & 0.11 \\
\hline
\end{tabular}

\section{Analysis of the abundance determinations and the results obtained}

The molybdenum abundances were determined for 13 giants in two OCs using stellar atmosphere models by Castelli \& Kurucz (2004), as well as a modified STARSP LTE spectral synthesis code (Tsymbal, 1996). For the used Mo I lines 5506 and $5533 \AA$ the oscillator strengths $\log g_{f}$ were adopted from the latest version of the VALD database dated 2016 (Kupka et al., 1999).

The processing of observed spectra (continuum definition, smoothing at three points etc.) was carried out using the DECH20 software package (Galazutdinov, 1992).

The examples of fitting the calculated spectra to the observed spectra of the star 5271 in the NGC 2506 cluster are shown in Figs. 1 and 2.

As can be seen from Figs. 1 and 2, the molybdenum line is in the wing of the iron line at $5506.493 \AA$ and $5533.031 \AA$ lines, respectively, i.e. it is blended by the iron line. This means that correct determination of the molybdenum abundance requires fitting the synthetic spectrum to the observed spectrum at the regions near the Fe lines $5506.440 \AA$ and $5532.870 \AA$, respectively; hence, we carried out such a fitting in this study.

Table 3 summarizes the resulting determinations of the molybdenum abundance, the root-mean-square (rms) deviations $\sigma$ and metallicities $[\mathrm{Fe} / \mathrm{H}]$ (Mishenina et al., 2015) for 13 giants in NGC 2477 and NGC 2506.

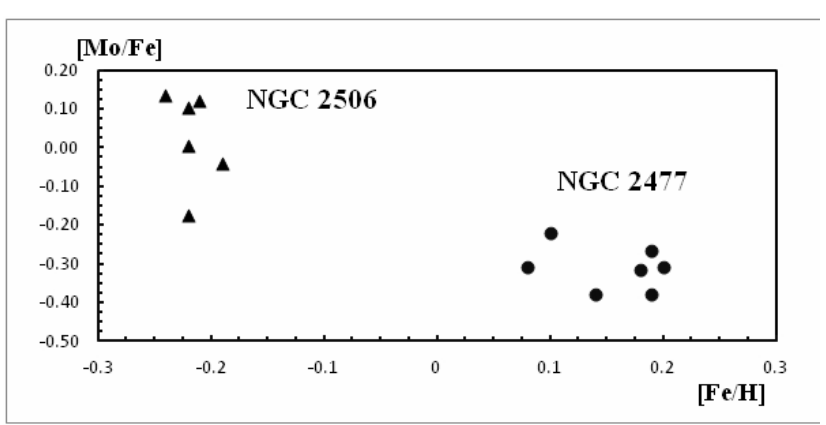

Figure 3: The dependence of the molybdenum abundance on the metallicity $[\mathrm{Fe} / \mathrm{H}]$ for all stars in the OCs NGC 2506 and NGC 2477.

The dependence of the molybdenum abundance on the metallicity $[\mathrm{Fe} / \mathrm{H}]$ in the investigated stars in NGC 2506 and NGC 2477 is shown in Fig. 3.

To determine the ratio between the Mo abundance and the solar $[\mathrm{Mo} / \mathrm{Fe}]$, the following data of the $\mathrm{Fe}$ and $\mathrm{Mo}$ abundances in the solar atmosphere were adopted from the study (Asplund et al., 2009): $\mathrm{Mo}=1.88, \mathrm{Fe}=7.50$.

\section{Conclusions}

The molybdenum abundances in NGC 2477 and NGC 2506 are close to the solar ones.

For the stars in NGC 2506, molybdenum is slightly overabundant as compared to its solar abundance; such an overabundance is slightly higher in the stars of the second investigated cluster NGC 2477.

In future in order to provide a detailed picture of the enrichment of open clusters in molybdenum, we are to determine the molybdenum abundances for a larger number of clusters and compare these data with those reported in the literature.

\section{References}

Asplund M., Grevesse N., Sauval, J. A., Scott P.: 2009, $A R A \& A, 47,481$.

Castelli F., Kurucz R.: 2004, preprint (ArXiv:0405087).

Galazutdinov G.A. Echelle spectra processing program package: 1992, Preprint SAO, N92.

Hansen C. J., Andersen A. C., Christlieb N.: 2014, $A \& A$, 568, A47.

Kupka F., Piskunov N., Ryabchikova T. A., et al., 1999, $A \& A S, 138,119$.

Mishenina T., Pignatari M., Carraro G., Korotin S., Shereta E., Yegorova I. and Herwig F.: 2015, MNRAS, 446, 3651.

Tsymbal V.: 1996, ASP Conf. Ser., 108, 198. 